\title{
Literatura, Sociedade e Identidade Cultural: Um diálogo entre "As mãos dos pretos", de Luis Bernardo Honwana, "Por que o negro é preto", de Câmara Cascudo, e Macunaíma, de Mário de Andrade
}

\author{
Laís de Almeida Cardoso ${ }^{1}$
}

\begin{abstract}
RESUMO: Literatura, sociedade e identidade cultural são áreas de estudo intimamente relacionadas, por meio das quais é possível construir uma ideia de nação. Neste artigo estudamos o conto "As mãos dos pretos", do moçambicano Luis Bernardo Honwana, paralelamente a dois textos brasileiros, "Por que o negro é preto", conto popular recolhido por Câmara Cascudo, e um trecho de Macunaíma, de Mário de Andrade, de modo a estabelecer um profícuo diálogo entre eles.
\end{abstract}

ABSTRACT: Literature, society and cultural identity are closely related fields of study, through which it is possible to settle an idea of nation. In this article we study the Mozambican Luis Bernardo Honwana tale "As mãos dos pretos" and confronted it with two Brazilian texts, "Por que o negro é preto", folktale collected by Câmara Cascudo, and a chapter of Macunaíma by Mário de Andrade, in order to establish a profitable dialogue between them.

PALAVRAS-CHAVE: Literatura Africana e Brasileira; Identidade Cultural; Sociedade; Conto Popular. KEYWORDS: African and Brazilian Literature, Cultural Identity; Society; Folktale.

Em um dos capítulos de seu livro Literatura e sociedade, Antonio Candido propõe uma reflexão sobre como fatores socioculturais podem influenciar o artista em seu processo criativo, considerando "em que medida a arte é expressão da sociedade", e "em que medida é social, isto é, interessada nos problemas sociais". Concluindo o capítulo, Candido define a relação entre obra, autor e público como "inextricável" do ponto de vista sociológico. Segundo ele, a arte é um "sistema simbólico de comunicação inter-humana", que "pressupõe o jogo permanente de relações entre os três", formando uma "tríade indissolúvel” (CANDIDO, 1967, p. 23).

Outra tríade que requer uma atenção especial em tempos de pós-modernidade é a formada por literatura, sociedade e identidade cultural, particularmente quando estudada pelo viés da Literatura Comparada, que nos permite situar o período sóciohistórico da nação em que a obra se insere, o contexto político e econômico da época em que a obra foi gerada, além das concepções histórico-culturais que integram não

\footnotetext{
${ }^{1}$ Mestre em Letras pela Universidade de São Paulo. Doutoranda em Estudos Comparados de Literaturas de Língua Portuguesa (FFLCH-USP).
} 
apenas a temática abordada, mas a ideologia inerente à estética proposta pelo autor. Nesse âmbito, o texto literário, muitas vezes, atua como substrato da sociedade na qual aquele projeto artístico foi concebido. Já a identidade cultural se constrói e se reconstrói no interior das trocas sociais, na correlação ou na contraposição com outras identidades.

Logo nos primeiros parágrafos de seu livro A identidade cultural na pósmodernidade, Stuart Hall define como prioridade em sua obra a exploração de questões sobre a "identidade cultural na modernidade tardia", e propõe uma avaliação sobre a existência de uma "crise de identidade". Promete ainda explorar alguns argumentos relacionados a identidades culturais - "aqueles aspectos de nossas identidades que surgem de nosso 'pertencimento' a culturas étnicas, raciais, linguísticas, religiosas e, acima de tudo, nacionais" (HALL, 2003, p. 7-8).

\begin{abstract}
A formação de uma cultura nacional contribuiu para criar padrões de alfabetização universais, generalizou uma única língua vernacular como o meio dominante de comunicação em toda a nação, criou uma cultura homogênea e manteve instituições culturais nacionais, como, por exemplo, um sistema educacional nacional. Dessa e de outras formas, a cultura nacional se tornou uma característica-chave da industrialização e um dispositivo da modernidade. Não obstante, há outros aspectos de uma cultura nacional que a empurram numa direção diferente, trazendo à tona o que Homi Bhabha chama de "a ambivalência particular que assombra a ideia da nação" (HALL, p. 49$50)$.
\end{abstract}

Para Hall, "as identidades modernas estão sendo 'descentradas', isto é, deslocadas ou fragmentadas", e a ideia de nação como uma "identidade cultural unificada" é utópica e inexistente. Algumas razões apresentadas pelo autor para corroborar essa dificuldade em estabelecer uma "identidade cultural nacional unificadora" são: a) "a maioria das nações consiste de culturas separadas que só foram unificadas por um longo processo de conquista violenta - isto é, pela supressão forçada da diferença cultural"; b) por serem "sempre compostas de diferentes classes sociais e diferentes grupos étnicos e de gênero"; c) devido à "hegemonia cultural" imposta pelos colonizadores "sobre as culturas dos colonizados" (HALL, p. 59-61).

Uma forma de unificá-las, segundo o autor, seria por meio da etnia - definida em seu livro como conjunto de características culturais (língua, religião, costume, tradições, etc.) que são "partilhadas por um povo". Porém o próprio Hall nos revela que essa unificação seria mais uma tentativa frustrada de se criar uma verdade baseada em um mito ou engodo, uma vez que toda nação é formada por uma confluência de culturas, e que "as nações modernas são todas híbridos culturais” (HALL, p. 62). 
Eurídice Figueiredo, discorrendo sobre literatura, nacionalidade e identidade, ratifica essa ideia, acrescentando que "a questão da identidade surge realmente como uma resposta às opressões sofridas pelos povos colonizados (...)" (FIGUEIREDO, 2002, 65-72):

(...) o negro no século XX (...) não sabe, naturalmente, que identidade (ou identidades) havia antes da escravidão, até porque antes do encontro com o homem branco não havia o negro. O negro, o colonizado e o oriental são invenções (constructos) da Europa (...). O colonizador europeu (...) tinha sua identidade, embora não se usasse então tal palavra (...) E no entanto todos nós sabemos que franceses e ingleses não tinham (e não têm) uma identidade nacional única, cada um desses povos possuindo seus mitos de origem (FIGUEIREDO, p. $65-72)$.

Benjamin Abdala Jr., no último capítulo de seu livro Literatura, história e política, também aborda o assunto, comparando as situações do Brasil e de países africanos de língua portuguesa na busca de uma identidade. Em seu texto, esclarece que, "ao assumirmos nossa identidade nacional, não nos reduzimos ao folclorismo passadista, mas propomos uma nova situação comprometida com a modernidade que nos envolve". Acrescenta ainda que "a autonomia de cada uma de nossas literaturas é uma conquista contínua contra as perspectivas alienantes dos modelos ideológicos neocolonialistas" (ABDALA JR., 2007, p. 254).

O novo canto africano, que surgia em torno da Segunda Grande Guerra, era motivado por uma situação que escapava ao rígido controle colonial. (...) Muitos dos textos produzidos nessa situação de ruptura para com os padrões metropolitanos só foram publicados no período pós-independência. Os novos cantos africanos seguiam as perspectivas rítmicas de cada um de seus países. Expressavam as suas vozes por sobre as formas de alienação metropolitanas. Eram gritos denunciadores do inconformismo de escritores pertencentes aos setores intelectuais e que procuravam uma identidade nacional no referente sociocultural do país (ABDALA JR., p. 254).

Já em Formação da Literatura Brasileira, Antonio Candido atribui à literatura papel fundamental na representação da pátria e das tradições, das crenças e das instituições de um povo:

Com efeito, a literatura foi considerada parcela dum esforço construtivo mais amplo, denotando o intuito de contribuir para a grandeza da nação. Manteve-se durante todo o Romantismo este senso de dever patriótico, que levava os escritores não apenas a cantar a sua 
terra, mas a considerar as suas obras como contribuição ao progresso (CANDIDO, 1975, p. 10).

Assim, do mesmo modo que no Brasil pós-colônia procurou-se constituir uma ideia de nação e de identidade por meio da literatura - especialmente a partir do século XIX, quando, independente de Portugal, o país sentiu a necessidade de criar uma imagem diferente daquela europeia, exaltando a figura indígena, "legítimo dono" da terra, como ícone do povo brasileiro (FIGUEIREDO, 2002) -, também as nações africanas de língua portuguesa têm na literatura pós-colonial uma voz de libertação. Um exemplo é a obra Nós matamos o Cão-Tinhoso (1964), do moçambicano Luis Bernardo Honwana:

\begin{abstract}
A obra Nós matamos o Cão-Tinhoso de Luís Bernardo Honwana, por meio de suas personagens afásicas, insinua a condição do homem colonizado, que teve a sua fala, a sua palavra interditada pelo colonizador. Insinua também a existência de falas que buscam a libertação, querendo-se realizar como força de gênese e epifania, construindo e anunciando um mundo próprio e melhor (...) A obra aparece em 1964, em plena ambiência da luta de libertação nacional, revelando a crueza, a violência do Estado colonial, que naquele momento sofria o enfrentamento instituído pelas forças revolucionárias (...) Valendo-se de um modo, de um estilo supra-real na composição de sua narrativa, o autor consegue exprimir, denunciar as relações absurdas que regem o mundo colonizado (EVARISTO, 2000, p. 227-239).
\end{abstract}

O conto “As mãos dos pretos", que integra a coletânea Nós matamos o CãoTinhoso, é o ponto de partida desta nossa análise, que buscará na literatura brasileira textos paralelos ao narrado por Honwana, procurando estabelecer um diálogo entre Brasil e África, e mostrar que temos em comum algo mais do que a nossa língua portuguesa e os repercutidos ecos da colonização.

\title{
Brasil e África: Textos Paralelos
}

Partindo dos conceitos levantados por Antonio Candido, Stuart Hall, Eurídice Figueiredo e Benjamin Abdala Jr., e com base na ideia de apropriação proposta por Affonso Romano Sant'Anna (SANT'ANNA, 2001), procederemos à análise do conto moçambicano "As mãos dos pretos", remetendo-o a duas obras brasileiras de referência: o conto popular "Por que o negro é preto", recolhido por Câmara Cascudo, e um episódio narrado no início do Capítulo 5 do livro Macunaíma, de Mário de Andrade. 
Os três textos em questão - em particular os dois primeiros, especialmente por pertencerem à categoria de conto (diferentemente de Macunaíma, que foi concebido em outro formato) - possuem um caráter etiológico, que, segundo a definição de Ribeiro, foram sugeridos ou inventados "para explicar e dar razão de ser um aspecto, propriedade, caráter de qualquer ente natural" (RIBEIRO, 1919 apud CASCUDO, 1998, p. 19).

\section{"As mãos dos pretos"}

No conto de Honwana, o narrador - uma criança, presumivelmente negra busca em sua memória e fornece ao leitor explicações que lhe foram dadas para o fato de as palmas das mãos dos negros serem mais claras do que a cor do restante de sua pele. Durante a narrativa, são relatadas respostas de pessoas que desempenham diferentes papéis: o "Senhor Professor" e o "Senhor Padre" (representando a escola e a igreja, respectivamente), a "Dona Dores", o "Senhor Antunes da Coca-Cola", o "Senhor Frias" e "Dona Estefânia", simbolizando diferentes profissões ou até mesmo classes sociais distintas. O texto também traz uma explicação colhida pelo narrador "em um livro" e revela no final a explicação "verdadeira", proferida por sua mãe.

As explicações à pergunta - Por que as mãos dos pretos são brancas? - podem ser assim resumidas, relatadas na ordem que aparecem no texto:

1. Os avós andavam como "bichos do mato", apoiados com as palmas no chão, que não eram expostas ao sol (Senhor Professor);

2. Os negros andavam de mãos postas a rezar e, assim, não as queimavam (Senhor Padre);

3. Deus fez as mãos dos negros brancas para não sujarem a comida dos patrões (Dona Dores);

4. Deus e outros santos confeccionaram os negros em barro com moldes usados, e os puseram a secar nas chaminés; as mãos ficaram brancas porque se seguraram enquanto o barro cozia (Senhor Antunes da Coca-Cola);

5. Deus acabava de fazer os homens e eram todos pretos; lavavam-se e saíam brancos; os que foram feitos de madrugada só tinham molhado as plantas das mãos e dos pés porque a água estava fria (Senhor Frias);

6. Os negros tinham a pele escura por viverem encurvados colhendo algodão (livro);

7. As mãos ficaram brancas por terem sido muito lavadas (Dona Estefânia); 
8. Para mostrar que as mãos dos homens são iguais (e que os homens são iguais), independentemente da cor da pele (Mãe).

Como é possível perceber, algumas das "explicações” enumeradas pelo narrador retomam o mito religioso da Criação. A mais explícita é a que faz referência ao barro com o qual Deus teria moldado o homem. Porém a explicação que nos chama a atenção para a intertextualidade com as outras obras que aqui analisaremos é a quinta relacionada acima, na fala do personagem Senhor Frias:

Deus acabava de fazer os homens e mandava-os tomar banho num lago do céu. Depois do banho as pessoas estavam branquinhas. Os pretos, como foram feitos de madrugada e a essa hora a água do lago estivesse muito fria, só tinham molhado as palmas das mãos e as plantas dos pés, antes de se vestirem e virem para o mundo (HONWANA, 1980).

A explicação do Senhor Frias vem precedida de uma "certeza absoluta", que é ratificada pelo personagem ao narrador:

Nesse mesmo dia, o Senhor Frias chamou-me, depois de o Senhor Antunes ter ido embora, e disse-me que tudo o que eu tinha estado para li a ouvir de boca aberta era uma grandessíssima peta. Coisa certa e certinha sobre isso das mãos dos pretos era o que ele sabia (HONWANA).

Desse modo, explorando uma curiosidade típica da infância na busca por uma resposta a uma dúvida existencial, Honwana consegue passar para o leitor a atrocidade criativa da mente humana, que revela todo o preconceito contido nas "despretensiosas" histórias narradas por seus personagens.

\section{"Por que o negro é preto"}

"Por que o negro é preto" é o título de um dos contos recolhidos por Câmara Cascudo que integram a coletânea Contos tradicionais do Brasil. No prefácio de seu livro, o autor explica a importância do conto popular e do folclore para a antropologia, para a história e a literatura, uma vez que eles ensinam "a conhecer o espírito, o trabalho, a tendência, o instinto, tudo quanto de habitual existe no homem" (CASCUDO, p. 9). 
Nenhuma ciência possui maior espaço de pesquisa e de aproximação humana do que o Folclore. (...) De todos os materiais de estudo, o conto popular é justamente o mais amplo e mais expressivo. E, também, o menos examinado, reunido e divulgado. Para centenas de volumes de versos populares, possuímos três ou quatro coleções de contos tradicionais. (...) $\mathrm{O}$ conto é um vértice de ângulo dessa memória e dessa imaginação. A memória conserva os traços gerais, esquematizadores, o arcabouço do edifício. A imaginação modifica, ampliando por assimilação, enxertos ou abandonos de pormenores, certos aspectos da narrativa. (...) $\mathrm{O}$ conto popular revela informação histórica, etnográfica, sociológica, jurídica, social. É um documento vivo, denunciando costumes, ideias, mentalidades, decisões e julgamentos. (...) Para todos nós é o primeiro leite intelectual (CASCUDO, p. 9-10).

Câmara Cascudo classifica os contos recolhidos em doze seções, entre os quais os contos etiológicos, categoria em que se encontra "Por que o negro é preto". Na abertura do conto, a questão proposta é: "Por que o negro tem a sola dos pés e a palma das mãos inteiramente brancas?", pergunta que nos remete imediatamente ao texto de Honwana. Diferentemente do que ocorre no texto moçambicano, entretanto, o personagem narrador do conto brasileiro não precisa ir atrás de diferentes respostas, já se conformando com a única explicação que tem. Neste caso, o "dono da verdade" é Mestre Alípio, um "vaqueiro conceituado, administrador do Engenho Itaipu", que faz seu relato nos moldes das narrativas populares. É o conto dentro do conto. Segundo o personagem, quando Cristo esteve na Paraíba, para "rondas de inspeção", uma mulher, que havia parido dezesseis vezes, envergonhada pela quantidade de filhos que teve em tão pouco tempo, escondeu metade das crianças em um quarto. Ao ser interrogada por Nosso Senhor sobre o que lá havia, a mulher mentiu, dizendo que era um depósito de carvão. Como castigo por sua mentira, todos os oito filhos que estavam no quarto saíram de lá pretos. Revoltada e triste, a mulher foi consolada por São Pedro, que a aconselhou a banhar seus filhos nas águas do Jordão. É nesse ponto que temos o principal contato com o texto de Honwana: havendo pouca água no rio, as crianças conseguiram molhar somente as solas dos pés e a palma das mãos:

Porém, quando a camponesa chegou com a metade de seus filhos às margens do rio sagrado, inexplicavelmente este se achava quase seco, com um fiozinho de nada correndo, mal chegando para que as crianças pudessem molhar a sola dos pés e a palma das mãos. E como estivessem com sede, beberam gotas apenas para enganar o desejo, resultando de tudo isso ficarem brancas aquelas partes do corpo, inclusive a boca (CASCUDO, p. 284). 
No texto moçambicano, o motivo pelo qual os pretos não teriam se banhado por inteiro no lago que os tornaria brancos foi a temperatura da água, que estava muito fria. Já no conto de Câmara Cascudo alega-se que havia falta de água em quantidade suficiente para lavar-lhes o corpo todo. Neste último acrescenta-se ainda a boca como parte do corpo cuja cor também fora modificada, ganhando tons "arroxeados".

A cada conto narrado nessa coletânea, Cascudo acrescenta notas explicativas. Nas notas sobre esse conto, em particular, o autor cita referências de outras versões, inclusive uma alemã "Naturgeschichtlich Volksmarchen", de Dahnhardt, e uma americana, "Why the negro is black", de Joel Chandler Harris (CASCUDO, p. 284286). O que mais chama a atenção, entretanto, é outra variante brasileira, de Medeiros e Albuquerque, na qual há ainda outros elementos interessantes a serem analisados. Nessa versão, conta-se que todos os homens que Deus criou (inclusive Adão) eram pretos, escuros como o barro. Porém, "complacente", Deus teria feito com que perto dali aparecesse "um lago de águas claras, onde quem se banhasse ficaria branco". De acordo com a narrativa, os primeiros que se banharam saíram brancos; os que já encontraram a água "suja" saíram em tons intermediários entre o branco e o preto; mas como a água foi-se acabando, restou para os últimos apenas um restinho no fundo, onde foi possível molhar somente as solas dos pés e as palmas das mãos.

Essa versão brasileira nos remete a um dos conhecidos episódios de Macunaíma, que acontece no quinto capítulo da obra de Mário de Andrade, no qual o herói - antes "preto retinto e filho do medo da noite" (ANDRADE, 2007, p. 11) - torna-se "branco loiro e de olhos azuizinhos" (ANDRADE, p. 50).

\section{Macunaíma}

Macunaíma é considerada uma rapsódia, tal a multiplicidade de mitos e lendas que compõem sua narrativa. Publicada em 1928, é uma das obras centrais do movimento antropofágico do Modernismo Brasileiro. De acordo com Telê Ancona Porto Lopes, estudiosa da obra de Mário de Andrade, Macunaíma é de um realismo que "lida com o mágico e com o maravilhoso" por meio de uma narrativa fantástica que agrega elementos culturais e folclóricos. O próprio autor define sua obra como "uma antologia do folclore brasileiro", revelando ter colhido elementos para sua narrativa mitos e lendas indígenas e folclóricas, sobretudo da recolha de Theodor Koch-Grünberg (1872-1924), etnógrafo e naturalista alemão responsável pelo registro dos mitos e lendas taurepangue e arekuná no início do século XX. 
Em 1926, ao ler sobre etnografia e cultura popular brasileira, encontra a figura de Makunaíma nos livros de mitos recolhidos pelo etnógrafo alemão Theodor Koch-Grünberg, na grande bacia amazônica. Tais mitos e lendas narram as aventuras dos heróis Taurepangue e Arekuná. Ao conhecer Makunaíma através dos estudos organizados pelo pesquisador alemão no início do século XX, Mário de Andrade se apaixona por esta personalidade mítica brasileira e o configura como o herói de nossa gente, dando vazão à criação de sua mais renomada obra (BARZOTTO, 2012).

Ao longo do texto, Mário de Andrade recria mitos indígenas em uma narrativa poética que busca o momento de criação não apenas de um país, mas de um povo inteiro. O herói sem nenhum caráter ${ }^{1}$ aos poucos vai se reconstruindo para criar essa identidade brasileira. Esse "nenhum caráter" de Macunaíma refere-se, segundo o autor, a uma moral em formação: "O brasileiro não tem caráter porque não possui nem civilização própria nem consciência tradicional (...) Está que nem o rapaz de vinte anos: a gente mais ou menos pode perceber tendências gerais, mas ainda não é tempo de afirmar coisa nenhuma" (OLIVEIRA \& SACCHETTA, 1999, p. 169).

Macunaíma é índio, porém preto, como o autor faz questão de frisar logo no início do livro.

No fundo do mato-virgem nasceu Macunaíma, herói de nossa gente. Era preto retinto e filho do medo da noite. Houve um momento em que o silêncio foi tão grande escutando o murmurejo do Uraricoera, que a índia tapanhumas pariu uma criança feia. Essa criança é que chamaram de Macunaíma (ANDRADE, p. 11).

No quinto capítulo, porém, dá-se a transformação do herói:

Uma feita a Sol cobrira os três manos duma escaminha de suor e Macunaíma se lembrou de tomar banho. Porém no rio era impossível por causa das piranhas (...). Então Macunaíma enxergou numa lapa bem no meio do rio uma cova cheia d'água. E a cova era que-nem a marca dum pé gigante. Abicaram. O herói depois de muitos gritos por causa do frio da água entrou na cova e se lavou inteirinho. Mas a água era encantada porque aquele buraco na lapa era marca do pezão de Sumé, do tempo em que andava pregando o evangelho de Jesus pra indiada brasileira. Quando o herói saiu do banho estava branco loiro e de olhos azuizinhos, água lavara o pretume dele. E ninguém seria capaz de indicar nele um filho da tribo retinta dos Tapanhumas (ANDRADE, p. 50).

\footnotetext{
${ }^{1}$ Caráter no sentido de conjunto de traços psicológicos que caracterizam um indivíduo ou um grupo.
} 
Na continuação da narrativa, os dois irmãos de Macunaíma - Jiguê e Maanape -, ao verem a metamorfose do protagonista, também desejam se lavar. Porém a água está "suja da negrura do herói” e Jiguê fica da "cor do bronze novo" (ANDRADE, p. 11). Quando chega a vez de Maanape, não sobra quase nada de água dentro da poça:

Tinha só um bocado lá no fundo e Maanape conseguiu molhar só a palma dos pés e das mãos. Por isso ficou negro bem filho da tribo dos Tapanhumas. Só que as palmas das mãos e dos pés dele são vermelhas por terem se limpado na água santa (ANDRADE, p. 50-51).

Esse último trecho assemelha-se à explicação dada por Mestre Alípio, no conto brasileiro "Por que o negro é preto". Embora o ato de lavar somente as palmas das mãos e as plantas dos pés nos três textos analisados tenha sido realizado por razões diferentes (em "Por que o negro é preto" e Macunaíma, por escassez de água; em "As mãos dos pretos", porque a água estava fria), o encaminhamento dado às narrativas é muito semelhante, o que nos aponta para uma matriz única, proveniente do mito e de longínquas narrativas orais.

\section{Religião e Preconceito}

Religião e preconceito são temas que afloram nos três textos analisados. Enquanto em Macunaíma predominam as citações de mitos e religiões aborígines, nos contos de Honwana e Cascudo sobressai-se a religião cristã, especialmente a católica.

Em “As mãos dos pretos”, a figura de Deus é citada explicitamente em três das oito explicações colhidas pelo narrador-personagem, e de forma implícita em mais uma delas, justamente na fala do Senhor Padre (representante da igreja), segundo o qual as mãos eram brancas porque "estavam sempre postas a rezar". Ou seja, metade das respostas colhidas pelo narrador apresenta um caráter religioso, o que não elimina o preconceito presente em todas elas. Pelo contrário; uma das explicações de cunho religioso, inclusive, vem acompanhada de um deboche típico da ironia e da zombaria:

Depois de contar isto, o Senhor Antunes e os outros Senhores que estavam à minha volta desataram a rir, todos satisfeitos (HONWANA, p. 76).

Já em "Por que o negro é preto", o aspecto religioso permeia toda a narrativa, com a presença de Jesus e seus apóstolos na Paraíba, fazendo "ronda de inspeção", acompanhada do caráter punitivo inerente à religião católica. No conto, a personagem 
que mente é castigada por Jesus. O preconceito vem acompanhado da punição: ser negro (ou ter os filhos transformados em negros), neste conto, é o "castigo":

Por causa de uma mentira se tornara mãe de oito filhos negros. Seu desgosto não podia ser senão enorme. Que fazer, então? Revoltada consigo mesma, não escondia a sua tristeza (CASCUDO, p. 283).

Não menos preconceituoso e religioso é o banho de Macunaíma e seus irmãos na cova que era a marca do pé gigante de Sumé, "do tempo em que andava pregando o evangelho de Jesus pra indiada brasileira" (ANDRADE, p. 50). No texto, o herói "consola" os irmãos que não conseguiram ficar totalmente brancos:

Macunaíma teve dó e consolou:

- Olhe, mano Jiguê, branco você ficou não, porém pretume foi-se e antes fanhoso que sem nariz (ANDRADE, p. 50-51).

Desse modo, nas três narrativas a religião é usada para justificar (ou até mesmo legitimar) o caráter extremamente preconceituoso com relação ao negro, relacionando a negritude à sujeira e a brancura à limpeza (Cascudo, Honwana e Andrade). Outros aspectos abordados são a semelhança do negro com o carvão (Cascudo e Honwana), com animais (Honwana), com castigo e punição (Cascudo e Honwana). Nos textos, Deus também é preconceituoso: fez os homens negros, mas deixou-lhes com as mãos brancas "para não sujar a comida que fazem para os seus patrões" (Honwana); moldouos com barro escuro, mas foi "complacente", criando o lago que os tornariam brancos (Cascudo); confeccionou-os em moldes usados e os pôs a secar em chaminés (Honwana).

Como é possível perceber, preconceito e religião são temas intimamente ligados e sobrepostos nos textos estudados. Analisar esses temas pelo viés da literatura pode ser um caminho para se tentar voltar ao passado e compreender melhor a formação da identidade de uma nação.

\section{A literatura e a construção de identidades}

Ainda em seu texto sobre literatura, nacionalidade e identidade, Eurídice Figueiredo afirma que "nos estudos culturais de hoje, falamos de construção de identidades, o que vale dizer que temos consciência de que as identidades são criações discursivas históricas" (FIGUEIREDO, p. 67). Mais à frente, cita a preocupação de 
Mário de Andrade em criar - em Macunaíma - uma "entidade brasileira" (FIGUEIREDO, p. 69):

No Brasil, como a tradição da nacionalidade (...) era muito forte, tendo sido reforçada inclusive no grande movimento de vanguarda que foi o modernismo, começou-se a falar de identidade nacional. Mário de Andrade (1978), no prefácio a Macunaíma (jamais publicado), explica a questão da falta de caráter do brasileiro. Diz que se interessou por Macunaíma devido à "preocupação em que vivo de trabalhar e descobrir o mais que possa a entidade nacional dos brasileiros" (...) Observe-se que ele usa a palavra "entidade" (...). E ele continua: "Ora, depois de pelejar muito verifiquei uma coisa que parece certa: o brasileiro não tem caráter" (...). Explica que entende por caráter não uma "realidade moral", mas a "entidade psíquica permanente, se manifestando por tudo, nos costumes na ação exterior no sentimento na língua na História na andadura, tanto no bem como no mal (FIGUEIREDO, p. 69).

Haroldo de Campos também explora a questão da identidade brasileira revelada por Mário de Andrade em seus escritos sobre Macunaíma:

Pode-se dizer que Mário de Andrade, na sua tentativa de sintetizar a cultura nacional, (...), de discernir uma "entidade nacional", homogênea, para além dos fragmentarismos geográficos e regionais (...), foi buscar na fábula, na gesta de Macunaíma, o necessário paralelo ordenador e estruturante (CAMPOS, 1973, p. 75).

O próprio Mário de Andrade assim o define:

Fiz questão de mostrar e acentuar que Macunaíma, como brasileiro que é, não tem caráter. Ponha reparo, ora é corajoso, ora covarde (DUARTE, 1985, p. 28-29).

É possível inferir, portanto, que o herói de Mário de Andrade nada mais é do que a representação de um povo ainda "sem caráter", que busca uma identidade nacional. O episódio do banho de Macunaíma e de seus irmãos pode ser visto como uma metáfora da formação do povo brasileiro: o índio negro, que deu lugar ao branco de olhos azuis (o europeu), e suas múltiplas miscigenações (o mulato, o cafuzo, o caboclo, o mestiço, o mameluco...).

Nas literaturas africanas de língua portuguesa também está clara a procura da construção de uma identidade perdida nos anos de colonização. Ana Mafalda Leite afirma que "as literaturas africanas de língua portuguesa encontraram maneiras próprias 
de dialogar com as 'tradições', intertextualizando-as no corpo linguístico" (LEITE, 2003, p. 21).

A enunciação dos legados culturais outros faz-se através do enunciado, que cumula e concentra (...) os ritmos híbridos da textualidade oral. É nesse trabalho da "língua" como texto (na acepção kristeviana) que se desvelam as "tradições" traídas, e reformuladas, e se recuperam os traços genealógicos de variadas "formas" ou "gêneros" orais, e outros gêneros provenientes da literatura. As literaturas africanas de língua portuguesa encenaram, deste modo, desde muito cedo, a criação de novos campos literários, fazendo coexistir na maleabilidade da língua, a escrita com a oralidade, numa harmonia híbrida, mais ou menos imparável, que os textos literários nos deixam fruir (LEITE, p. 21).

Já Manuel Ferreira refaz em seu estudo a trajetória das literaturas africanas lusófonas, mostrando como elas primeiramente refletem uma consciência regional, depois uma consciência política, para em seguida delinear uma estrutura ideológica:

Como quer que seja, as literaturas africanas de expressão portuguesa primeiro anunciam uma consciência regional, depois refletem uma consciência política, para em seguida determinar-lhes uma estrutura ideológica. Antecipam-se à luta armada, como que a prenunciam, e latente se mantém nos mais esclarecidos produtores de textos a integração devotada ao mundo real da transformação a caminhão da liberdade futura e total (...) Somente agora que a libertação chegou para todos esses povos, os seus escritores vão encontrar as condições essenciais para a revelação do seu mundo total. É uma literatura (...) que lança com frequência seu apelo à Mãe-África (...) e também à exortação do homem negro, numa identificação coletiva, havendo nela, permanente, o protesto, a fraternidade racial, a acusação (...) É uma literatura localizada mas ecumênica, embora por várias razões nem sempre tivesse podido (...) ir beber lá onde as estruturas sociais africanas mantêm a raiz de uma tradição milenar (FERREIRA, 1987, p. 206-207).

Desse modo, além da língua portuguesa e dos famigerados ranços da colonização, Brasil e África podem encontrar na literatura outras possibilidades de diálogo, sobretudo nos textos que advêm da cultura oral, carregados de signos e significados das nossas mais profundas origens, raízes, crenças e tradições populares.

\section{Considerações Finais}

No segundo capítulo de seu livro De voos e ilhas: literaturas e comunitarismos, intitulado "Fronteiras de solidariedade", Benjamin Abdala Jr. escreve: 
Ninguém cria do nada. Há a matéria da tradição literária que o escritor absorve e metamorfoseia nos processos endoculturativos, desde a apreensão "mais espontânea" dos pequenos "causos" populares, ditos populares, canções etc., da chamada oralitura ("literatura" oral) até os textos "mais autorreflexivos" da literatura erudita. Ocorre, nesse sentido, uma apropriação "natural" das articulações literárias sem que o próprio futuro escritor se aperceba de sua situação de ser social e de "porta-voz" de um patrimônio cultural coletivo (ABDALA JR., 2003, p. 112).

Mais à frente, o autor complementa a ideia de "apropriação" proposta por Affonso Romano Sant'Anna (SANT'ANNA, p. 43-50):

Não vemos a apropriação apenas como uma estratégia discursiva
consciente do escritor. Trata-se, conforme indicamos, de uma
apreensão intertextual e inter-semiótica múltipla da série literária em
relação dialética com outras séries culturais. É também um trabalho
literário de apropriação da cultura, de sentido político-social, mas que
o sujeito não domina plenamente. (...) A apropriação não se restringe
apenas a uma operação de colagem ou de bricolagem, como aparece
nas artes modernas e contemporâneas, uma forma de
"dessacralização" do objeto artístico. (...) Na apropriação inerente à
produção cultural, a fusão intertextual é múltipla e cada segmento ou
instância discursiva dialoga em vários níveis com o conjunto da vida
cultural (ABDALA JR, p. 113).

Desse modo, é possível inferir que o diálogo proposto entre os três textos analisados nesta pesquisa tenha se estabelecido por meio de uma fonte comum, proveniente da sabedoria popular. Se "Por que o negro é preto" advém sabidamente da cultura oral, o mesmo pode-se dizer tanto de Macunaíma (rapsódia formada, segundo o próprio autor, por uma colagem de textos folclóricos) como de "As mãos dos pretos", cujo repertório essencial com que o texto é construído remete à forma do conto popular.

Câmara Cascudo define as características que atribuem ao conto popular esse aspecto ao mesmo tempo particular e universal, único e múltiplo, capaz de nos surpreender ao mesmo tempo por sua simplicidade e ambivalência:

As características do conto popular são, para mim: a) antiguidade; b) anonimato; c) divulgação; d) persistência. É preciso que o conto seja velho na memória do povo, anônimo em sua autoria, divulgado em seu conhecimento e persistente nos repertórios orais (CASCUDO, p. 10$11)$. 
Também Héli Chatelain (1859-1908)², na introdução à edição bilíngue de seus Contos populares de Angola, atribui aos contos papel revelador para se tentar recuperar a constituição de uma nação:

Em África, onde não é fácil o contato íntimo com os nativos, e onde não existe uma literatura escrita, o único meio de penetrar no caráter e na forma moral e intelectual das raças e tribos é fazer um estudo completo das suas instituições sociais e religiosas, e da sua literatura oral, ou seja, do seu folclore. (...) O folclore africano não é uma árvore isolada, mas um ramo de uma árvore universal (CHATELAIN, 1964).

Setenta anos após a publicação dos contos angolanos de Chatelain, e, coincidentemente, no mesmo ano em que a obra do filólogo suíço é traduzida pela primeira vez para o português, Luis Bernardo Howana remove a areia e traz à tona por meio de "As mãos dos pretos" o preconceito explícito que cerca sua etnia.

De acordo com Conceição Evaristo, não apenas esse conto, mas todos os textos de Nós matamos o Cão-Tinhoso são caracterizados por apresentar uma fantasia que “cumpre o papel de revelar a realidade" (EVARISTO, p. 227):

Os fatos, as imagens, tudo que compõe a matéria narrativa toma dimensões fantásticas, absurdas, extrapolando o real histórico, diluindo a fronteira entre o real e o irreal. Valendo-se de um modo, de um estilo supra-real na composição de sua narrativa, o autor consegue exprimir, denunciar as relações absurdas que regem o mundo colonizado (EVARISTO, p. 227).

Ainda segundo a autora, nos contos de Honwana "a narração e a apreensão da realidade se dão muitas vezes pelo olhar, pela percepção da criança” (EVARISTO, p. 228). Então, assim como no conhecido conto de Andersen, em que o olhar da criança revela que "o imperador está nu", é também por meio desse olhar infantil que, em "As mãos dos pretos", o narrador elege a mãe como "a única a ter razão sobre essa questão de as mãos de um preto serem mais claras do que o resto de seu corpo" HONWANA, p. 77), pois é a palavra da mãe que "denuncia a arbitrariedade do colonizador e anuncia a igualdade dos homens" (EVARISTO, p. 229).

\footnotetext{
${ }^{2}$ Linguista das Missões Independentes em África, filólogo e apaixonado pelo folclore africano, poliglota (francês, alemão, inglês, italiano, grego, latim, hebraico), estudou durante os anos em que esteve em Angola a língua portuguesa e a língua nativa (quimbundo).
} 


\section{Referências Bibliográficas}

De voos e ilhas: Literatura e comunitarismos. Cotia: Ateliê Editorial, 2003.

ABDALA JR., Benjamin. Literatura, história e política. Cotia, Ateliê Editorial, 2007.

ANDERSEN, Hans Christian. A roupa nova do Imperador. São Paulo, Brinque-Book, 1997.

ANDRADE, Mario de. Macunaíma: o herói sem nenhum caráter. Revisão de Telê Porto Ancona Lopez e Tatiana Longo Figueiredo. Rio de Janeiro: Agir, 2007.

BARZOTTO, Leoné Astride. "A construção da identidade cultural por meio do texto literário pós-colonial: Brasil e Guiana". In: PINHEIRO, Alexandra S.; BUNGART NETO, Paulo (Orgs.). Estudos culturais e contemporaneidade: literatura, história e memória. Dourados: UFGD, 2012.

CAMPOS, Haroldo de. Morfologia do Macunaíma. São Paulo: Perspectiva, 1973.

CANDIDO, Antonio. Literatura e sociedade. São Paulo: Nacional, 1967.

Formação da Literatura Brasileira, vol. 2. $5^{\text {a }}$ ed. São Paulo: USP, 1975.

CASCUDO, Câmara. "Prefácio". In: Contos tradicionais do Brasil. Rio de Janeiro: Ediouro, 1998, p. 9-21.

"Por que o negro é preto". In: Contos tradicionais do Brasil. Rio de Janeiro: Ediouro, 1998, p. 283-84.

CHATELAIN, Héli. Contos populares de Angola: cinquenta contos em quimbundo. Lisboa: Agência-Geral do Ultramar, 1964.

DUARTE, Paulo. Mário de Andrade por ele mesmo. São Paulo: Hucitec, 1985.

EVARISTO, Conceição. "Luís Bernardo Honwana: Da afasia ao discurso insano em Nós matamos o Cão-Tinhoso". In: SEPÚLVEDA, Maria do Carmo \& SALGADO, Maria Teresa (Orgs.). África \& Brasil: letras em laços. Rio de Janeiro: Atlântica, 2000, p. 227-239.

FERREIRA, Manuel. Literaturas africanas de expressão portuguesa. São Paulo: Ática, 1987.

FIGUEIREDO, Eurídice. "Literatura, nacionalidade e identidade". In: REIS, Livia de Freitas \& PARAQUETT, Márcia (Orgs.) Fronteiras do Literário II. Niterói: EdUFF, 2002, p. 65-72.

HALL, Stuart. A identidade cultural na pós-modernidade. 11ª ed. Rio de Janeiro: DP\&A, 2003.

HONWANA, Luis Bernardo. “As mãos dos pretos”. In: Nós matamos o cão tinhoso. São Paulo: Ática, 1980, p. 75-77.

LEITE, Ana Mafalda. Literaturas africanas e formulações pós-coloniais. Lisboa: Colibri, 2003.

OLIVEIRA, Elvira de \& SACCHETTA, José (Orgs.). "Para entender Macunaíma". In: ANDRADE, Mario de. Macunaíma. São Paulo: Klick, 1999.

RIBEIRO, João. O folk-lore. Rio de Janeiro: s.ed., 1919.

SANT’ANNA, Affonso Romano. Paródia, paráfrase \& CIA. São Paulo: Ática, 2001, p. 43-50. 